\title{
BILATERAL LYMPHOSARCOMA OF THE THIRD EYELID IN A DOG
}

\author{
WOUK, A.F.P.F.'; CÍRIO, S. ${ }^{2}$ KASECKER, G.G. ${ }^{3}$; SOUZA, A.L. ${ }^{4}$ \\ ${ }^{1}$ Departamento de Medicina Veterinária - UFPR; \\ ${ }^{2}$ Pontifícia Universidade Católica do Paraná; \\ ${ }^{3}$ Curso de Pós-Graduação em Ciências Veterinárias, UFPR; \\ ${ }^{4}$ Curso de Graduação em Medicina Veterinária - UFPR.
}

A two years old non spayed female dog of Fila Brasileiro breed was received at the Hospital, with a history of hyperemia and upwards deviation of the left eye and hyperemia on the right eye. On the ophtalmic examination, the right third eyelid was protruding, thickened and hyperemic and the left eye third eyelid displaced forwards (covering the whole cornea), hyperemic and thickened. This eye showed dorsal divert revealing pain to orbit palpation. When nictitating membranes from both eyes were reversed, an increase of volume of its internal surface could be verified. The left eye displayed a mass not observed in the right eye, prolonged itself aborally and ventrally to the bulb of the eye, chemosis and superficial keratitis with edema and pannus. The animal was weak, lethargic but did not show satellite lymphatic involvement. Radiographic exam did not reveal any thoracic or abdominal changes. X-rays from head showed increase in volume and opacity of soft tissues from the left orbit, without changes on the bony parts. Complete blood cell count evidenced hypochromic macrocytic anemia, leucocytosis with lymphocytosis and thrombocytopenia. An important finding from blood biochemistry was hypercalcemia (19 $\mathrm{mg} / \mathrm{dl})$. Based upon clinical findings, radiological findings and laboratory data, a neoplasia was suspected. Exenteration of left orbit was carried on, together with surgical resection of the right eye third eyelid. Histological examination of this material revealed lymphosarcoma of the right third eyelid and lymphosarcoma of the left eye third eyelid with invasion of sclera, muscular and retro orbital regions. Therapy was then proposed by means of vincristine as base drug with cyclophosphamide, metotrexate and prednisone, but the dog's owner did not agree to proceed with due to its high cost. Under these conditions the dog was sent home, returning after 30 days with dysphagia and cachexia. Mandibular lymphnodes and tonsils were enlarged. The owner then agree to give the dog $2 \mathrm{mg} / \mathrm{kg}$ of prednisone intravenously every other day, which caused a decrease in limphnodes size, disappearance of dysphagia and improvement of the body general state. Sixteen days after the first consultation, the patient returned in extreme weakness and comatose. Then, due to the dog pitiful clinical picture and at the owners request euthanasia was accomplished. Lymphosarcoma of the third eyelid is a rare ocular neoplasia and, in this case, displaying an uncommon characteristics of incidence in such as a young animal with bilateral condition. Surgical treatment was indicated because masses were easily accessible, but the absence of chemical therapy resulted in the patient's short survival.

Key Words: dog, lymphosarcoma, third eyelid. 